\title{
Land-Sea Interactions in Punta China (Baja California, México): Addressing Anthropic and Natural Disturbances in a Retrospective Context
}

\author{
Guillermo Torres-Moye ${ }^{1}$, Anamaría Escofet ${ }^{*}$ \\ ${ }^{1}$ Department of Biology, Faculty of Marine Sciences, Autonomous University of Baja California, Ensenada, \\ Mexico \\ ${ }^{2}$ Department of Marine Ecology, Center of Scientific Research and High Education of Ensenada, Ensenada, \\ Mexico \\ Email: gtorres@uabc.edu.mx, ${ }^{*}$ aescofet@cicese.mx
}

Received 29 September 2014; revised 26 October 2014; accepted 18 November 2014

Copyright ( 2014 by authors and Scientific Research Publishing Inc.

This work is licensed under the Creative Commons Attribution International License (CC BY). http://creativecommons.org/licenses/by/4.0/

(c) (i) Open Access

\begin{abstract}
In extensive SCUBA-diving surveys of kelp forests along $350 \mathrm{~km}$ of the Baja California peninsula coastline from the US-México borderline to Sacramento Reef, benthic species richness has been satisfactorily explained by environmental structural features such as bottom rugosity. However, values at Punta China embayment (PCE) departed significantly from the model whereas the adjacent Santo Tomás cove (STC) did not. In addition, in August 20, 2011, visibility was under $1 \mathrm{~m}$ at PCE and over $10 \mathrm{~m}$ at STC; these conditions presumably reflect the influence of the limestone extraction industry located on land. In order to investigate the case allowing for temporal comparisons, we set a regional research scenario similar to a 1993 pioneer study, comprising PCE and two contrasting sites (STC to the North, and San José embayment, SJE, to the South). Land and sea side were addressed separately, and a 1950-2012 time-span period was set in order to perform the analysis of retrospective data. Our results suggest that the current scenario results from the combined influence of a local, anthropic and chronic land-based disturbance represented by the progressive expansion of limestone extraction industry, and the episodic influence of a natural, large scale and acute disturbance represented by the 1982-83 and 1997-98 El Niño events. The influence of both driving forces, however, is not necessarily equally distributed in space, yielding a regional mosaic of natural and social conditions. Our results confirm and expand previous knowledge in the area, and may contribute to future basic and applied research.
\end{abstract}

${ }^{*}$ Corresponding author.

How to cite this paper: Torres-Moye, G. and Escofet, A. (2014) Land-Sea Interactions in Punta China (Baja California, México): Addressing Anthropic and Natural Disturbances in a Retrospective Context. Journal of Environmental Protection, 5, 1520-1530. http://dx.doi.org/10.4236/jep.2014.516144 


\section{Keywords}

\section{Mexican Pacific Embayments, Mining Industry, El Niño Events, Kelp Beds, Safari Method}

\section{Introduction}

The analysis of retrospective data is a well-established procedure for tracking and organizing the ecological and social events that occur in a given area of interest in space and time. Such an approach for setting historical and spatial contexts is increasingly needed in the assessment of ecosystems quality and carrying capacity considering natural and man-made driving forces [1].

Understanding processes underlying observed patterns is particularly challenging in coastal scenarios, where land uses are mainly associated with the solid face and the liquid face is associated with the arrival of natural and man-made items from the adjacent land. In such a context, the systematic analysis of retrospective data is relevant in order to address the chain of causal relationships between human activities and changes in the ecological system, in order to identify and organize the state of physical and biotic elements of the territory, as well as social factors acting to provide goods and services, or, in a management-oriented approach, in order to organize all the former and thus encourage conflict resolution and sustainable use projection [2] [3].

Here we describe, for the 1950-2012 period, a coastal scenario encompassing three embayments that display the combined yet uneven influence of a local, anthropic and chronic land-based disturbance represented by the progressive expansion of limestone extraction industry, and the episodic influence of natural, large scale and acute disturbances represented by the 1982-83 and 1997-98 El Niño events, yielding a regional mosaic of natural and social conditions.

Our results confirm and expand pioneer findings by [4] and may contribute to future basic and applied research in the area.

\section{Methods}

\subsection{Observed Scenario}

Extensive SCUBA-diving surveys of kelp forests along $350 \mathrm{~km}$ of the Baja California peninsula coastline from the US-México borderline to Sacramento Reef have shown that benthic species richness was satisfactorily explained by bottom rugosity [5]. However, at Punta China embayment, PCE, $20 \mathrm{~km}$ south of Ensenada, benthic species richness was significantly lower than the predicted by the model, whereas at the adjacent Santo Tomás cove, STC, only $2 \mathrm{~km}$ to the North, it was consistent with the model, and very close to the PCE predicted value (Figure 1).

These results brought to our mind field conditions observed at PCE in 2011, when $17 \mathrm{~m}$ deep rocky bottoms 3 km away from the coastline, were heavily covered with fine sediments, and high turbidity (visibility under 1 m) precluded satisfactory and safe diving. In contrast, low turbidity (10 m visibility) and no fine sediments on the rocky bottom were observed at STC (Figure 2).

At that point, we posed two basic research questions: what elements would be necessary to explain quite different visibility at two embayments only few km apart? How would this be related to the fact that one site fitted the rugosity-species richness model whereas the other did not? This in turn brought to mind a 1993 pioneer survey [4] in which a gradient of $\mathrm{CaCO}_{3}$ (calcium carbonate) in sediments, as well as changes in algal abundance and species composition occurred in PCE according to the influence of sediments originated at the barge-loading and deposit sites of the limestone extraction industry located on land, whereas contrasting values occurred at STC to the North, and San José embayment, SJE, to the South (Figure 3).

\subsection{Approach}

Having examined the features of the observed scenario, we became convinced that accounting for events related to anthropic sediment inputs would be relevant in explaining the conditions surrounding kelp beds in PCE and STC in 2011. Accordingly, we set a research scenario with a regional approach similar to the one established in 


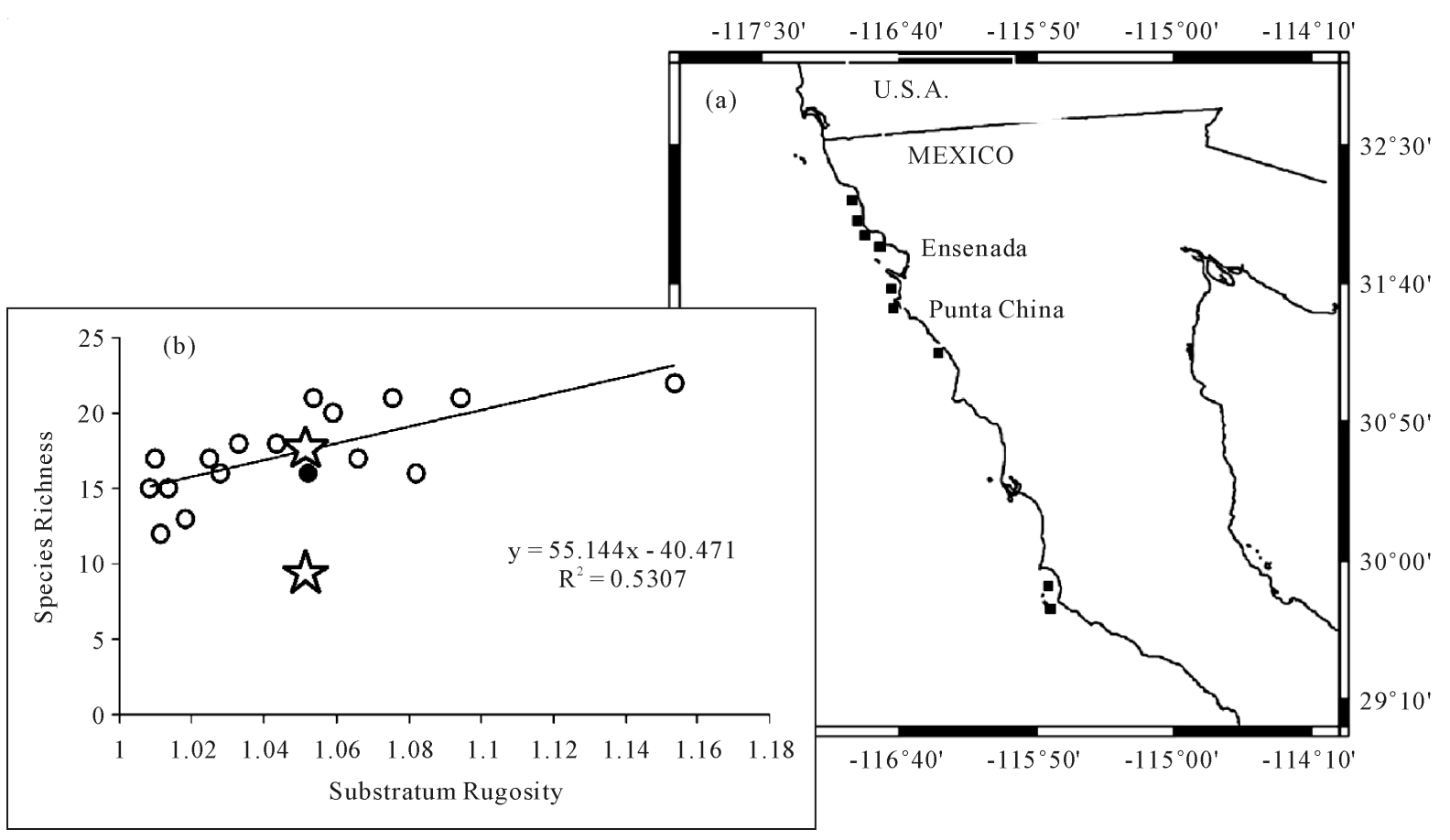

Figure 1. The area covered by the ten sites included in extensive kelp beds surveys (a) and the relationship between bottom rugosity and species richness (b). Observed and expected values at Punta China embayment are indicated by low and high stars respectively. Observed value at Santo Tomás cove is in full circle. Source: Torres-Moye et al., forthcoming.
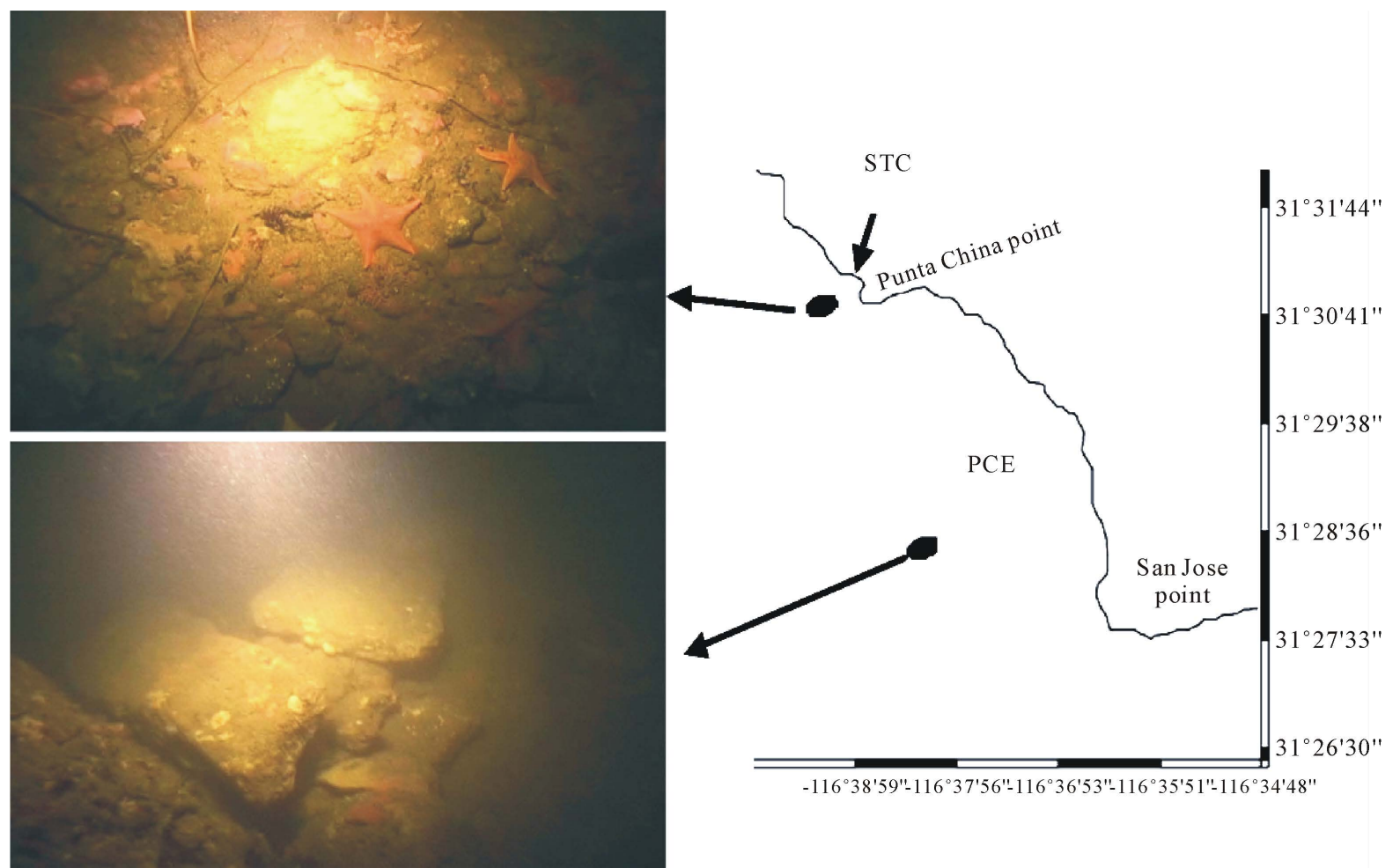

$-116^{\circ} 38^{\prime} 59^{\prime \prime}-116^{\circ} 37^{\prime} 56^{\prime \prime}-116^{\circ} 36^{\prime} 53^{\prime \prime}-116^{\circ} 35^{\prime} 51^{\prime \prime}-116^{\circ} 34^{\prime} 48^{\prime \prime}$

Figure 2. Seafloor conditions at Punta China embayment (PCE) and Santo Tomás cove (STC) showing high turbidity and almost bare bottom in the first, and good visibility and conspicuous bottom species in the second. Pictures were taken on August $12^{\text {th }}, 2011$ with only one hour difference (10:00 and 11:00 hrs. respectively). Source: original pictures by G. TorresMoye. 


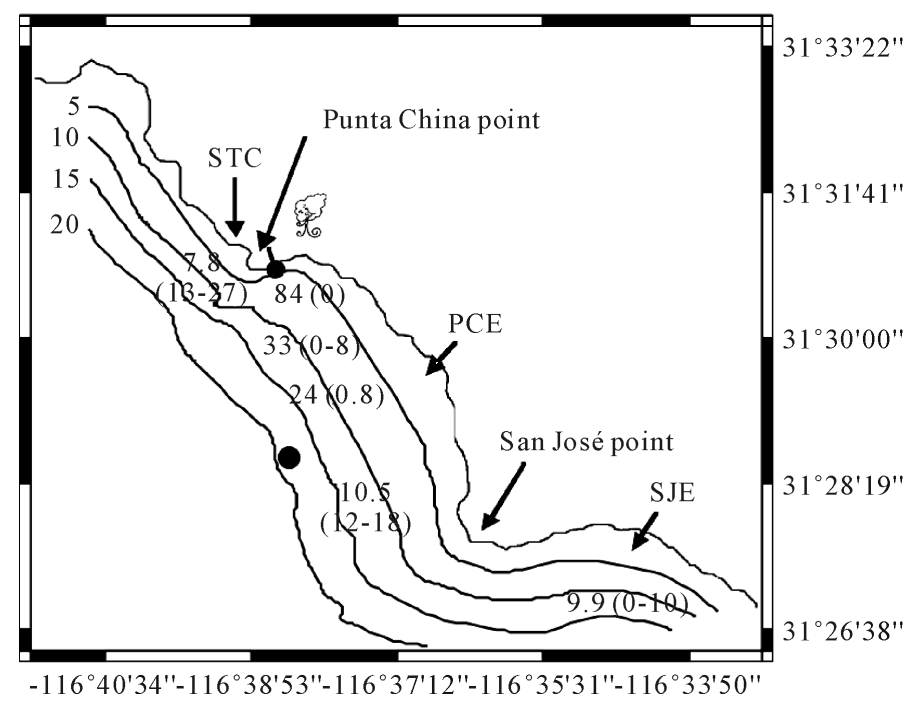

Figure 3. The 1993 gradient of $\mathrm{CaCO}_{3}$ in sediments and algal density at PCE and at the contrasting North and South sites (STC and SJE) according to the influence of sediments originated at the barge-loading and deposit sites of the limestone extraction industry located on land. Percent $\mathrm{CaCO}_{3}$ in sediments is in plain numbers; numbers in parenthesis are the range of percent cover by $M$. pyrifera in the bottom. The tip-rounded arrow indicates the sediment jet produced by the loading maneuver at the barge-loading site. The blowing face image indicates transportation via wind and eventual runoff from the deposit site. Location of the 2011 field observation is in dark circle. Isobaths (plain numbers upper left) are in meters. Source: this study, on the basis of [4].

1993 by [4]: PCE at the center and two contrasting North and South sites (STC and SJE), comprising around 13 $\mathrm{km}$ coastline ( 0.63 for STC, 7.0 for PCE and 5.5 for SJE).

As a starting point in the research process, we adopted some essential philosophical and methodological principles for performing the analysis of retrospective data: 1 ) an attitude or purpose of coherently stringing together past events; 2) recognition that traces or remnants of such events emerge as scattered individual stories that may formally belong to different disciplines; 3 ) recognition that traces and individual stories may not be measurable in conventional units accepted by formal sciences, and that an active search for methods that can build a methodological bridge with other disciplines is needed (historical reconstructions, semi-quantitative or qualitative analysis, non-linear effects) [1] [2].

\subsection{Procedure}

For gathering of retrospective data, land and ocean sides were addressed separately, and a 1950-2012 time-span period was set. In general, this phase was guided by the safari method [1] in the sense that past events that may have conducted to the present condition we want to explain are immersed in an unknown terrain in which data that would make sense for the explanation we are looking for have to be chased and selected progressively.

Regarding the limestone extraction industry, a 1997 geological chart from the Mexican Geological Service was used to identify the limits of the original limestone deposit. INEGI 1993 and 2009 aerial photos were used to recognize the extent of the extraction areas, which were distinguished as clear "scars" left by the removal of coastal shrub vegetation. Land runoffs of extraction areas were identified at a 1:50,000 scale with the watershed fluxes simulator program (National Institute of Statistics, Geography and Informatics, INEGI by the Spanish acronym).

For the kelp forest, the following sources were employed: a 1968 aerial photograph from [6]; a 1985 satellite image from [7]; data of the 1993 bottom percent cover by M. pyrifera from [4], a 2006 aerial image from INEGI, and a 2009 NOAA ASTER image. For the 1968 data, the surface borders of the kelp canopy were digitalized 
and their corresponding areas estimated using Google Earth Pro. For the 1993 data, range of bottom cover was set over kelp silhouettes mimicking the 1985 image.

In addition, conversations with key informants such as long-term residents and fishermen were held. During meetings, we first described the field conditions we found in 2011 and then asked how they would explain them. Informants were two members of the local fishing groups (R. León-Amador, a long-term fisherman, and D. León, formerly a fisherman and an executive director now) and D. Sánchez-Lora, a former production manager at AGARMEX (Spanish acronym for the Mexican agar-producing industry).

\section{Results}

Our results confirm and expand previous knowledge in the area. Specifically, we suggest that the current scenario is a result of the combined influence of a local, anthropic and chronic land-based disturbance represented by the progressive expansion of limestone extraction industry, and the episodic influence of natural large scale and acute disturbances represented by the 1982-83 and 1997-98 El Niño events. However, due to the spatial setting of the limestone bed, which is physically separated from STC and encompasses only the PCE and SLE surroundings, the influence of both forces is not necessarily equally distributed in space, yielding a regional mosaic of natural and social conditions.

\subsection{Land Side: Mining Industry}

The original limestone bed, nearly $7.5 \mathrm{~km}^{2}$ in area, extends about $8 \mathrm{~km}$ in a NW-SE direction. It is naturally confined to PCE and SJE land areas, and has no spatial relation with STC for a mountain ridge clearly separates to the North the area where STC is located (Figure 4).

Limestone exploitation started in 1950 at the northern tip of the limestone bed. At the time, a $2.5 \mathrm{~km}$ transport road was built, a circa $250 \times 80 \mathrm{~m}$ grinding and deposit area was installed at the base of Punta China point, and a barge-loading site was installed at the very tip of Punta China point. By 1993 the extraction area was $0.23 \mathrm{~km}^{2}$. In 2009, a new $0.15 \mathrm{~km}^{2}$ extraction area adjacent to the first was opened. Individual micro-watersheds, $0.5 \mathrm{~km}$ apart, are associated with each exploitation area (Figure 5).

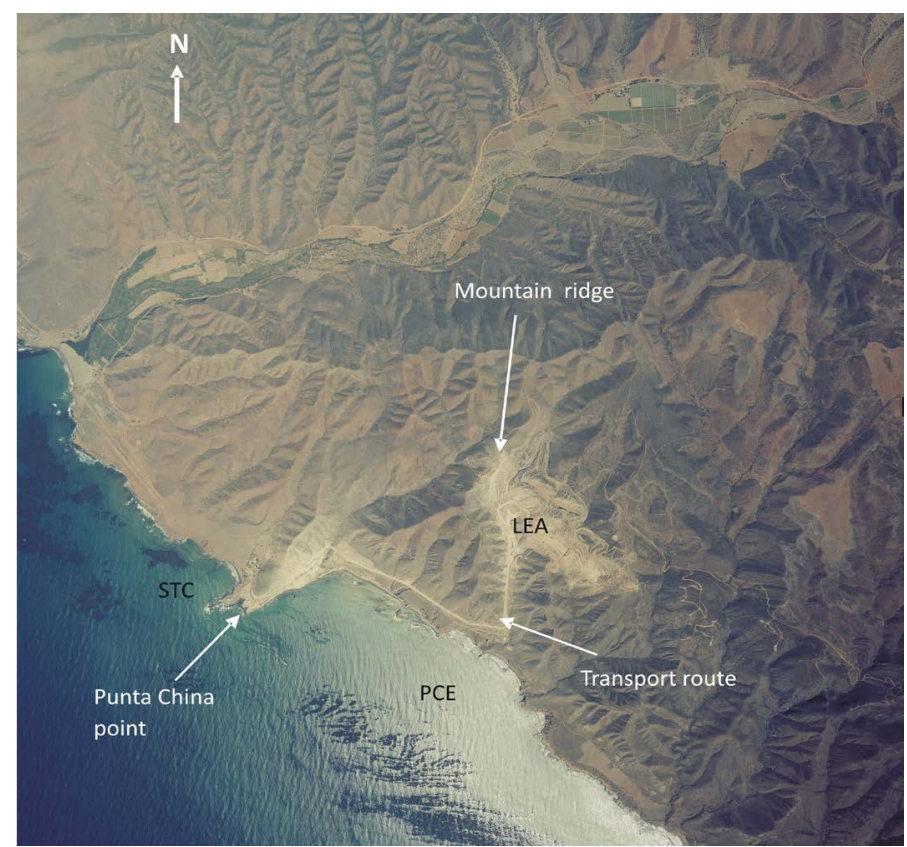

Figure 4. Aerial image of Punta China point, showing PCE to the South and STC to the North, and the mountain ridge that confines the limestone bed to the South. Also shown is the transport road from the extraction area to the deposit and barge-loading sites. Source: aerial image by INEGI, 2006. 


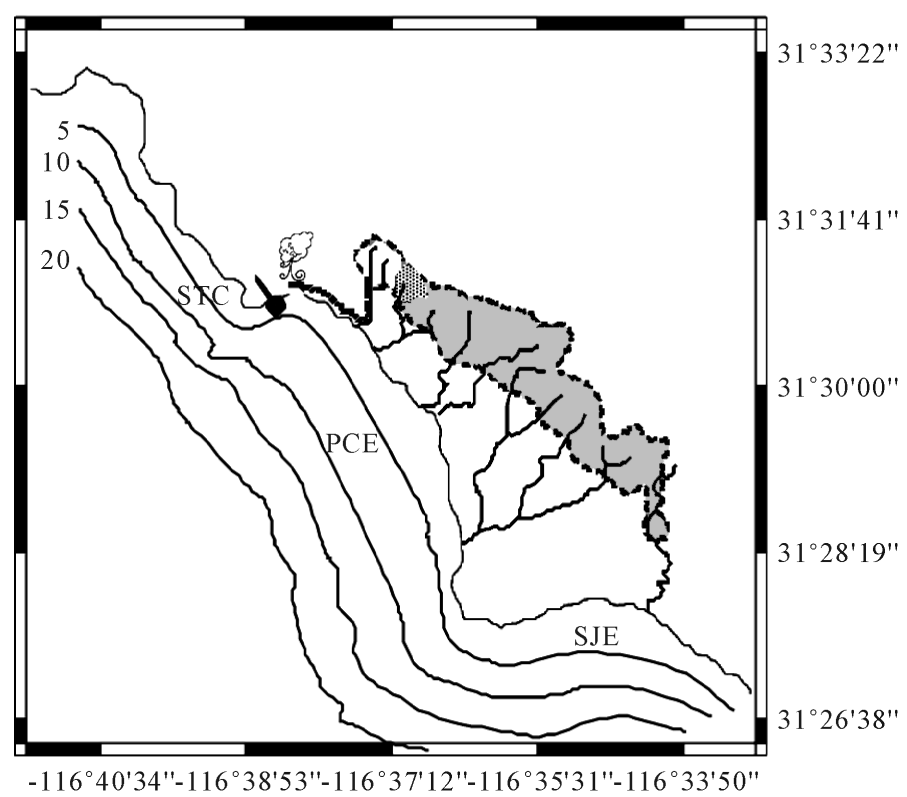

Figure 5. Limits of the original limestone bed (dashed lines), and the scope of extraction areas, EA. The 1950-93 EA is in white, the 1993 to date EA is dotted. The remnant deposit is in dark gray. The limestone rocks transportation road is in dotted line. Blowing face image and tip-rounded arrow are as in Figure 3. Watershed runoff effluents include those flowing from the remnant deposit, indicating that could become active in the future. Source: this study, on the basis of the 1997 geological chart by the Mexican Geological Service, 1993 orthophoto and 2009 INEGI H11B22 aerial images, and INEGI fluxes simulator program. Source: this study.

Barge-loading site, deposit site, and extraction areas are sources of limestone particles that would eventually reach the ocean and become visible as water-suspended particles which in turn disperse by advection and deposit on the bottom. These sources differ regarding the way in which they let off limestone particles: the bargeloading site is a point source in which a conspicuous cloud of air-suspended particles is visible around the loading jet; the deposit site is a heap source from which particles can be moved by wind and eventually by runoff; exploitation areas are bare ground sources from which particles can also be moved by wind or runoff; the transport road itself may also be considered as a non-point source from which particles are transported mainly by wind.

\subsection{Sea Side}

\subsubsection{Kelp Beds}

Around 1950-60, according to key informants, kelp forest surface canopy cover at Punta China embayment was abundant, and a significant exploitation of agar-producing species (Macrocysis pyrifera, Gelidium robustum and Gigartina canaliculata) existed.

In 1968, the estimated area of surface canopy cover of M. pyrifera was $3.5 \mathrm{~km}^{2}$ for PCE kelp bed, about 0.8 $\mathrm{km}^{2}$ for STC bed, and $0.4 \mathrm{~km}^{2}$ for the SJE bed (Figure 6(a)). According to key informants, beds were as continuous, extremely dense and compact as they had been in 1950-60. In fact, one of them stated that "they were so dense that you could almost walk on them", and a formidable picture by [6] shows the trail left on the canopy by the kelp harvest boat.

In 1982-83, kelp beds at a regional level were destroyed by a severe El Niño event; according to key informants, recovery was somehow visible by 1984.

By 1985, the PCE kelp bed was clearly fragmented in two, whereas those at STC and SJE were still continuous (Figure 6(b)). 

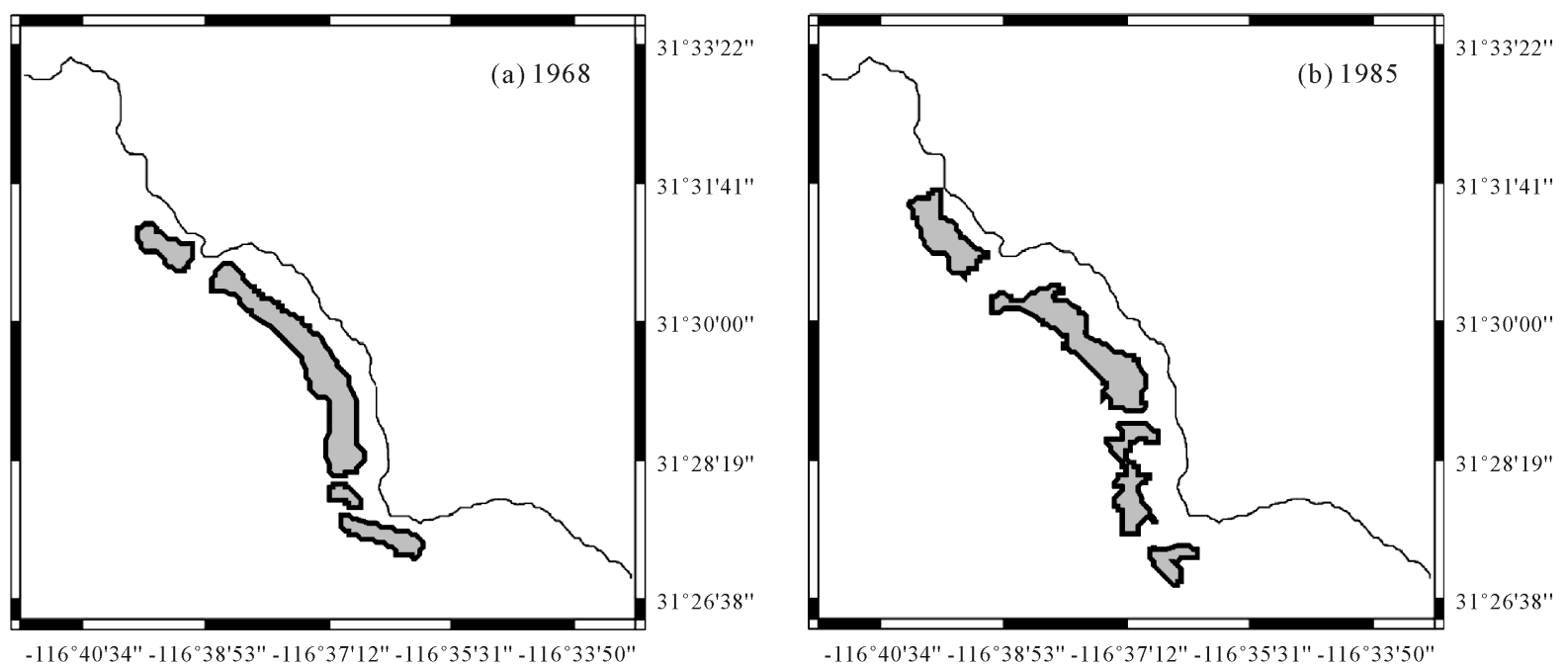

$-116^{\circ} 40^{\prime} 34^{\prime \prime}-116^{\circ} 38^{\prime} 53^{\prime \prime}-116^{\circ} 37^{\prime} 12^{\prime \prime}-116^{\circ} 35^{\prime} 31^{\prime \prime}-116^{\circ} 33^{\prime} 50^{\prime \prime}$

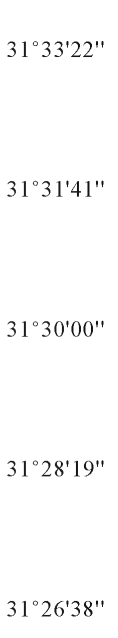

$-116^{\circ} 40^{\prime} 34^{\prime \prime}-116^{\circ} 38^{\prime} 53^{\prime \prime}-116^{\circ} 37^{\prime} 12^{\prime \prime}-116^{\circ} 35^{\prime} 31^{\prime \prime}-116^{\circ} 33^{\prime} 50^{\prime \prime}$

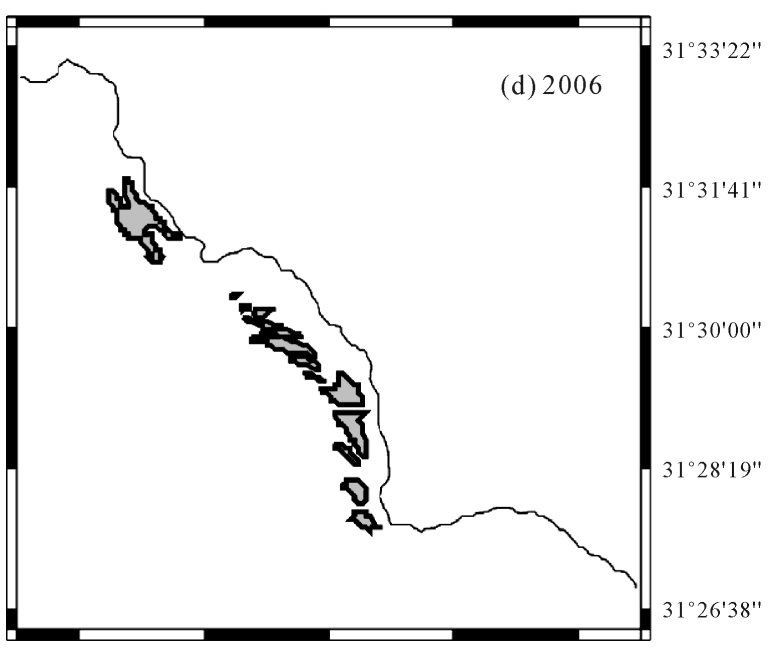

$-116^{\circ} 40^{\prime} 34^{\prime \prime}-116^{\circ} 38^{\prime} 53^{\prime \prime}-116^{\circ} 37^{\prime} 12^{\prime \prime}-116^{\circ} 35^{\prime} 31^{\prime \prime}-116^{\circ} 33^{\prime} 50^{\prime \prime}$

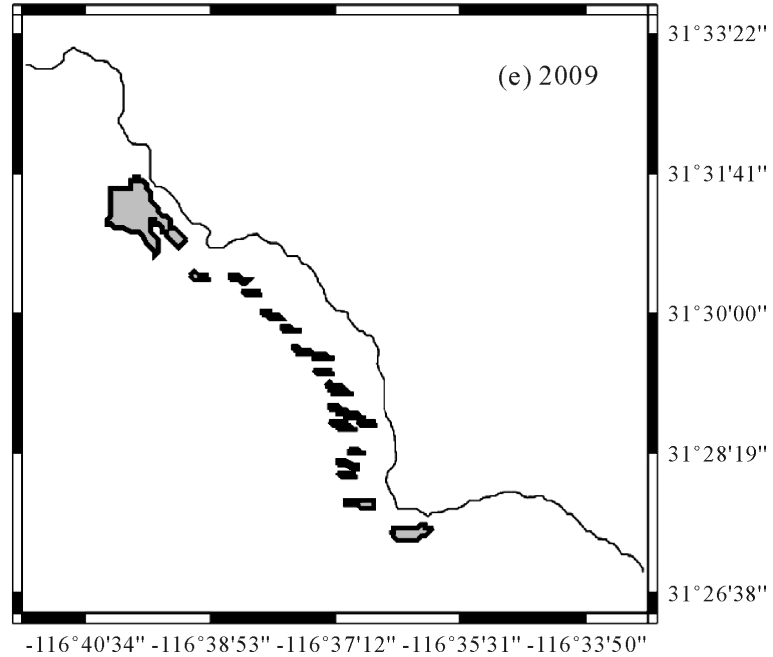

Figure 6. Kelp beds at Punta China embayment and Santo Tomás embayment along time. (a), (b), (d) and (e) were redrawn respectively from aerial photography by [6], satellite image by [7], aerial image from INEGI, 2006 and NOAA ASTER image 2009; in (c) ranges of bottom cover in 1993 [4] were set over kelp silhouettes mimicking the 1985 image. Sources: this study. 
By 1993, data of bottom percent cover by M. pyrifera were coherent with the 1985 condition: $13 \%-27 \%$ at STC, $0 \%-8 \%$ at the PCE northern patch, $12 \%-18 \%$ at the PCE southern patch and $0 \%-10 \%$ at SJE (Figure 6(c)). Also, a complete replacement of $M$. pyrifera by Halydris dioica occurred at the spot adjacent to the bargeloading site, with huge amount of $\mathrm{CACO}_{3}(84 \%)$ in sediments (see Figure 3).

In 1997-98, kelp beds at a regional level were again destroyed by a severe El Niño event.

By 2001-02, a general recovery of Baja kelp forests was reported [8] although no specific mention to particular scenarios was made.

By 2006-09, the PCE kelp bed was very to extremely fragmented in 11 - 15 small and narrow patches, whereas that at STC was still continuous and the one at SJE was somehow reduced (Figure 6(d) and Figure 6(e)).

By 2012, according to key informants, the PCE kelp bed was only 20\% of the 1960-70 accounts.

\subsubsection{Visibility}

Key informants stated that during the 1970-82 decade, corresponding to the sea-urchin fishery climax, no signs of turbidity were perceived. However, by 1985-86, turbidity due to fine sediments was perceived by sea-urchin fishermen at PCE, in the vicinity of the barge-loading and deposit sites, and visibility under $2 \mathrm{~m}$ forced them to move south, where normal visibility still occurred. These conditions had persisted at the site, or were at least noticeable during the 1993 assessment. In 1998, the exploitation of the agar-producing algae Gelidium at the whole PCE was suspended due to high turbidity. One testimony pointed out that by 1999, as part of compensatory actions fishermen were demanding, the limestone extraction industry installed sediment traps in the runoffs in order to reduce the amount of incoming sediments. Traps stayed in place only a few months and were eventually destroyed by the next rainy season.

On the basis of these testimonies and our 2011 field observations, we assembled a spatial gradient of goodbad visibility through time, setting at $2 \mathrm{~m}$ critical visibility for safe diving/fishing. Temporal and spatial progression of low visibility seems evident at PCE, where a transit from good to bad conditions arose first in the vicinity of the barge-loading and deposit sites, and later further south. In contrast, no such a transit occurred at STC, where visibility in 1993 and 2011 was equally good. In turn, the spatial and temporal gradient at PCE suggests that it could eventually spread to SJE, favored by prevailing circulation and advection pattern (Figure 7).

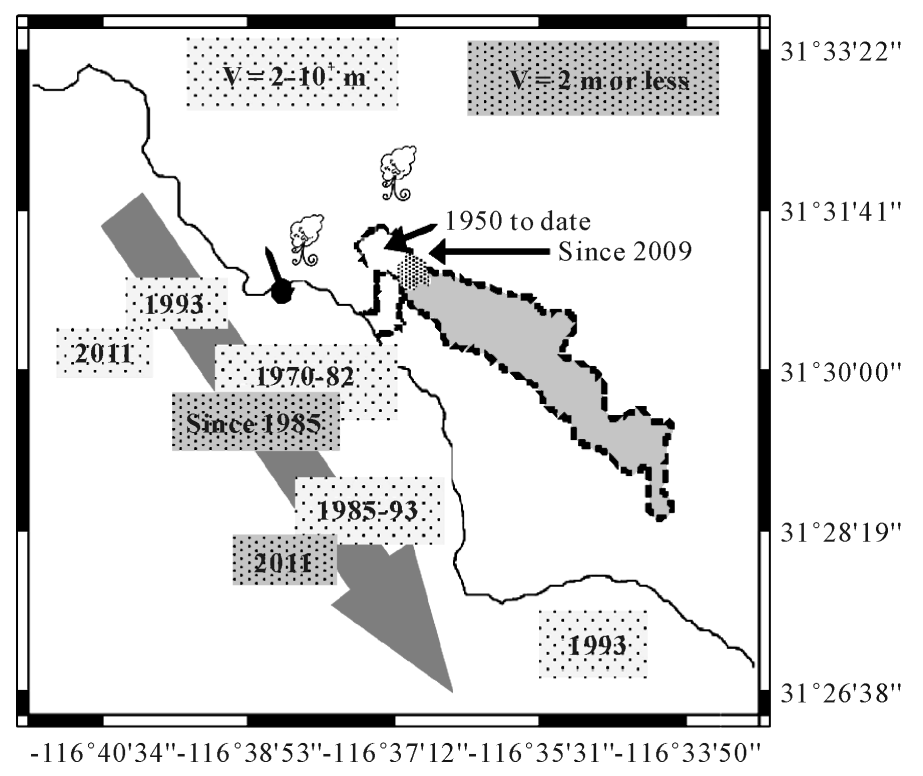

Figure 7. The gradient of visibility (V) along time at PCE and the contrasting conditions North and South (STC and SJE). Codes for visibility are operational and refer to the $2 \mathrm{~m}$ value as the critical level for safe diving. Gray arrow on back indicates prevailing circulation and advection process patterns. Limits of the original limestone bed and scope of extraction areas are as in Figure 5. Blowing face image and tip-rounded arrow are as in Figure 3. Source: this study. 


\subsection{Integrated Account of Land-Sea Interactions}

Currently, the influence of the land-based disturbances is palpable at PCE, seems to be progressing toward SLE, and is not evident at STC. On the other hand, different influence of the sea-side disturbance can be seen in the progressive fragmentation of kelp bed at PCE, with little change at STC and SJE. This can be explained by the following sequence of events.

In 1950, when limestone industry started operating, kelp beds were in the lush phase described by key informants and illustrated by Figure 6(a). Due to the spatial setting of the limestone bed, which is physically separated from STC and encompasses only the PCE and SJE surroundings, arrival of sediments released by limestone industry occurred mainly at PCE (Figure 4, Figure 5 and Figure 7). Later, the reduction of current speeds within the kelp forest (e.g. [9]), may have increased the sedimentation rates of the arriving suspended particles. This condition lasted for 30 years, until the 1982-83 El Niño event destroyed all kelps at a regional scale.

During the recovery process after El Niño event, the presence of sediments accumulated on the bottom became ecologically significant: it is a fact barely relevant for a well-established kelp but crucial for the attachment of microscopic stages of giant kelp. Consequently, recovery process initiated in two quite different conditions: rocky bottoms partially covered by limestone particles at PCE (a condition that may preclude successful attachment) and normal rocky bottoms at STC. This would explain that by 1985, canopy cover at STC was entirely similar to the previous 1968 image whereas at PCE the original kelp had split in two distinct patches (Figure 6(b)).

Extreme patchiness of PCE kelp in 2006 and 2009 (Figure 6(d) and Figure 6(e)) bolsters the idea of failures in kelp recruitment due to increased sedimentation rates, and suggest that after the 1997-98 El Niño event bottom conditions were similar or even worse than after the previous event, a reasonable outcome considering that a second limestone extraction area was operating since 1993, with the consequential increase in sediment arrival.

Temporal and spatial progression of low visibility, in turn, is consistent with the former general framework.

\subsection{Implications for Future Research}

Two features are crucial for future basic and applied research in the area 1) the cement industry is a major man-made driving force locally bounded by the spatial setting of the limestone bed, which is physically separated from STC and encompasses only the PCE and SLE surroundings; 2) limestone exploitation will reasonably last for decades, insofar as only $1 / 15^{\text {th }}$ of the limestone bed is being exploited after 70 years of extraction.

In such a context, the 13 - $15 \mathrm{~km}$ long coastal area described above becomes a unique scenario with three distinct sites: PCE would be the site to observe the combined influence of both land-based anthropic disturbance and the sea-based natural disturbance, SJE becomes a control site to follow the progressive influence of advected sediments and the eventual arrival of sediments by runoff as new limestone extraction areas are added: and STC emerges as a control site where limestone influence is physically precluded.

\section{Discussion and Conclusions}

Our study describes in a 1950-2012 time-span period a coastal scenario encompassing three adjacent embayments that display the combined yet uneven influence of a local, anthropic and chronic land-based disturbance represented by the progressive expansion of limestone extraction industry, and the episodic influence of natural, large scale and acute disturbances represented by the 1982-83 and 1997-98 El Niño events, yielding a regional mosaic of natural and social conditions.

The safari method approach [1] was fundamental to recover two pieces of information that were crucial for the analysis: 1) the pioneer study in the area [4] in which land and sea sides were addressed, and 2) the early document [6] in which canopy cover images that wouldn't be retrievable even by the more sophisticated contemporary technology are presented. The way we conducted meetings with key informants differ from current interviews in the sense that instead of asking for the way they acted in the past, we asked for explanations they might have for the conditions we faced in the field. That opened a peer to peer approach that elicited confidence to share experience without fear of being judged. That is the reason we prefer the term conversations for that part of our research.

The thorough spatial setting of the limestone bed is a novel contribution of our study that complements and expands the scenario presented in [4] in at least two ways: 1) limestone bed being physically separated from 
STC and encompassing only the PCE and SLE surroundings, and 2) full description of sources of limestone particles associated with different maneuvers of the mining industry, as well as corresponding ways in which each source let off limestone particles.

Another contribution of this study would be the description of temporal changes in the kelp beds addressing simultaneously the continuous long term inputs from land. The negative effect of sediment outflow on kelps has been largely acknowledged, although most refer to massive runoffs, and despite how severe damages could be, recovery usually occurs soon after (e.g. [10]). On the other hand, recovery after El Niño events has been addressed thoroughly [8] [11]. However, to our knowledge, the condition of kelp beds has never been related with continuous, long term land-based sources of sediments. In our case a parallel comparison of El Niño events in a long term sediment-impacted scenario (PCE) and a non-sediment impacted scenario (STC) can be portrayed, including sediments accumulated on the bottom being crucial for the recovery process due to sensibility of microscopic stages of giant kelp [12] yet barely significant for well-established kelps.

The way we addressed the visibility issue is somehow unusual, since turbidity is usually treated in a more formal expression. However, on the basis of testimonies and our own field experience regarding how low visibility elicited changes in fishing and diving maneuvers, we considered visibility as experienced turbidity and assembled a spatial gradient of good-bad visibility through time that was in turn consistent with the general pattern of land-sea interactions.

Our study addressed retrospective data that were relevant to unfold the initial idea that accounting for events related to anthropic sediment inputs would be relevant to address our basic research questions. The $13-15 \mathrm{~km}$ long coastal area we described becomes a unique scenario that combines 1) an experimental site (PCE) in which the combined influence of both land-based anthropic disturbance and the sea-based natural disturbance occur; 2) a major control site (STC) with null influence of limestone sediments and 3) a secondary control site (SJE) to follow the progressive influence of advected sediments and the eventual arrival of sediments by runoff as new limestone extraction areas are added. In that sense, our study would meet early recommendations to treat manmade projects as experiments at a spatial scale much larger than any scientific experiment [13].

Considering that our results complement and expand previous knowledge in the area, we feel confident that they will positively contribute to future basic and applied research.

\section{Acknowledgements}

This paper is a partial result of the CICESE internal project Interfase processes in the Mexican Pacific and its importance for benthic resources in which AE is the main responsible and both authors participate. Field observations were financed by CONACYT-SEMARNAT project \#107758 granted to the Autonomous University of Baja California, in which GTM participates. We remain indebted to our main Institutions for encouraging interinstitutional research efforts. We are deeply grateful to S. Guzmán del Próo and L. Salgado-Rogel for generous sharing of documents and experience. M. Mondragón (CICESE) assisted with general editing. Prompt English editing by L. Orensanz is kindly appreciated.

\section{References}

[1] Jansson, B. and Stalvant, C. (2001) The Baltic Basin Case Study-towards a sustainable Baltic Europe. Continental Shelf Research, 21, 1999-2019. http://dx.doi.org/10.1016/S0278-4343(01)00039-5

[2] Vestal, B. and Rieser, A. (1995) Methodologies and Mechanisms for Management of Cumulative Coastal Environmental Impact. Part I: Synthesis, with Annotated Bibliography. NOAA Coastal Ocean Program, Decision Analysis Series, 6, 1-133.

[3] Olsen, S.B. (2003) Frameworks and Indicators for Assessing Progress in Integrated Coastal Management Initiatives. Ocean \& Coastal Management, 46, 347-361. http://dx.doi.org/10.1016/S0964-5691(03)00012-7

[4] Salgado-Rogel, L. (1995) Benthic Biota in the Vicinity of Punta China (BC, México): A Comparative Study at Three Sites under Disturbance of Limestone Material and Sea-Urchin Exploitation. MSc Thesis, CICESE, Ensenada.

[5] Torres-Moye, G., Edwards, M.S. and Montaño-Moctezuma, C.G. (2013) Benthic Community Structure in Kelp Forests from the Southern California Bight. Ciencias Marinas, 39, 239-252. http://dx.doi.org/10.7773/cm.v39i3.2250

[6] Guzmán del Próo, S.A., de la Campa, S. and Granados-Gallegos, J.L. (1971) The Giant Kelp (Macrocystis pyrifera) and Its Exploitation in Baja California. Journal of the Mexican Society of Natural History, 32, 15-49.

[7] Reed, D.C. (2010) SBC LTER: Reef: Historical Kelp Database for Giant Kelp (Macrocystis pyrifera) Biomass in Cal- 
ifornia and Mexico. Santa Barbara Coastal LTER; Long Term Ecological Research Network. http://dx.doi.org/10.6073/pasta/74d5336cf9f1297b475db8ec6ed08819

[8] Edwards, M.S. (2004) Estimating Scale-Dependency in Disturbance Impacts: El Niños and Giant Kelp Forests in the Northeast Pacific. Oecologia, 138, 436-447. http://dx.doi.org/10.1007/s00442-003-1452-8

[9] Gaylord, B., Rosman, J., Reed, D., Koseff, J.R., Fram, J., MacIntyre, S. and Mardian, B. (2007) Spatial Patterns of Flow and Their Modification within and around a Giant Kelp Forest. Limnology and Oceanography, 52, 1838-1852. http://dx.doi.org/10.4319/lo.2007.52.5.1838

[10] Foster, M.S. and Schiel, D.R. (2010) Loss of Predators and the Collapse of Southern California Kelp Forests (?): Alternatives, Explanations and Generalizations. Journal of Experimental Marine Biology and Ecology, 393, 59-70. http://dx.doi.org/10.1016/j.jembe.2010.07.002

[11] Dayton, P.K. and Tegner, M.J. (1984) Catastrophic Storms, El Niño, and Patch Stability in a Southern California Kelp Community. Science, 224, 283-285. http://dx.doi.org/10.1126/science.224.4646.283

[12] Devinny, J.S. and Volse, L.A. (1978) Effects of Sediments on the Development of Macrocystis pyrifera Gametophytes. Marine Biology, 48, 343-348. http://dx.doi.org/10.1007/BF00391638

[13] National Research Council (1986) Ecological Knowledge and Environmental Problem-Solving. National Academic Press, Washington DC. http://dx.doi.org/10.2307/2260216 
Scientific Research Publishing (SCIRP) is one of the largest Open Access journal publishers. It is currently publishing more than 200 open access, online, peer-reviewed journals covering a wide range of academic disciplines. SCIRP serves the worldwide academic communities and contributes to the progress and application of science with its publication.

Other selected journals from SCIRP are listed as below. Submit your manuscript to us via either submit@scirp.org or Online Submission Portal.
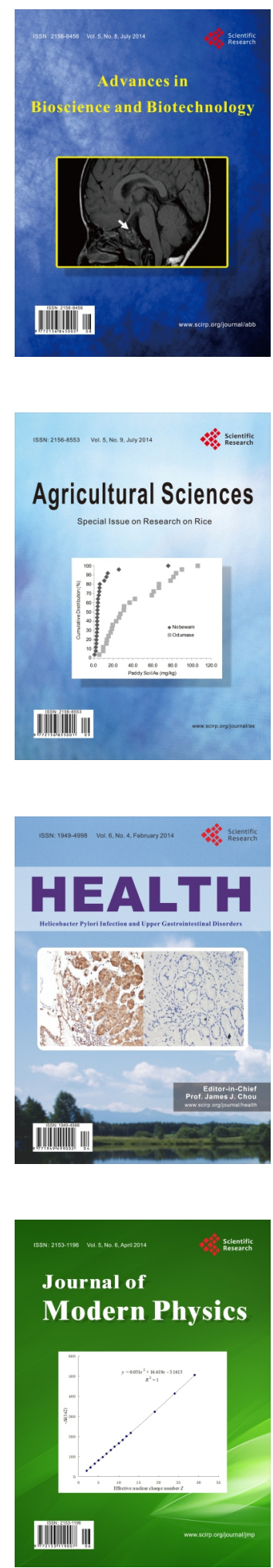
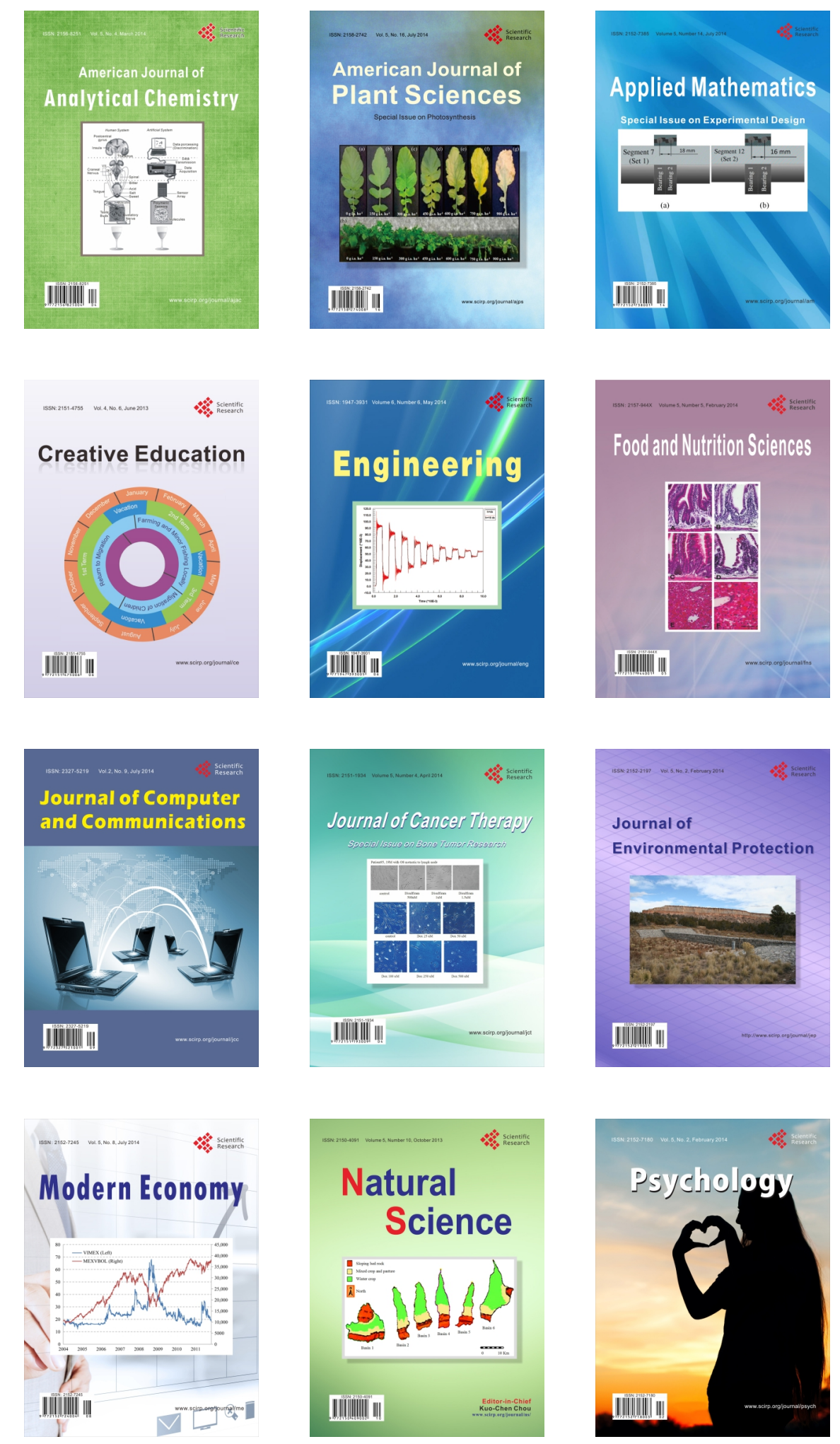